\title{
IMPLEMENTATION OF RISK ANALYZER MODEL FOR UNDERTAKING THE RISK ANALYSIS OF PROPOSED Building Projects For a SELECTEd Client
}

\author{
Ibrahim Yakubu \\ Department of Quantity Surveying, Faculty of Environmental Design, Abubakar Tafawa \\ Balewa University, P.M,B. 0248, Bauchi, Bauchi State, Nigeria
}

\begin{abstract}
The model of RISK ANALYZER was implemented as Knowledge-based System for the purpose of undertaking risk analysis for proposed construction projects in a selected domain. The Fuzzy Decision Variables (FDVs) that cause differences between initial and final contract sums of building projects were identified, the likelihood of the occurrence of the risks were determined and a Knowledge-Based System that would rank the risks was constructed using JAVA programming language and Graphic User Interface. The Knowledge-Based System is composed a Knowledge Base for storing data, an Inference Engine for controlling and directing the use of knowledge for problem-solution, and a User Interface that assists the user retrieve, use and alter data in the Knowledge Base. The developed Knowledge-Based System was compiled, implemented and validated with data of previously completed projects. The client could utilize the Knowledge-Based System to undertake proposed building projects
\end{abstract}

\section{Keywords}

RISK ANALYZER, Risk analysis, Knowledge-Based Systems, JAVA, Graphic User Interface

\section{INTRODUCTION}

The ability to see into the future and predict what could happen to a project once construction is underway would certainly serve to arm the Project Manager against project failures caused by escalation in construction costs and or escalations in contract periods. To look into the future and exactly foresee future events is by no means an easy or albeit; even a possible task. it is a talent possessed only by soothsayers and persons gifted with miraculous powers. At the construction project management level, however, to be able to predict project 'behavior' will make possible the erection of contingency plans that will absorb any consequences of events that have been foreseen. A model of the risk analysis process will simulate the expertise of construction professionals who have compiled heuristics that they in predicting and managing construction risk.

Ibrahim (2008) and Ibrahim (2010) proposed a model entitled 'RISK ANALYZER' for the purpose of undertaking risk analysis for a selected client and has recommended the adoption of the model as a conceptual framework for the development of a Knowledge-Based System that could be used for the risk analysis of construction projects in specific domains. 


\section{FRAMEWORK FOR THE MODEL}



Figure 1: Flow chart for risk analysis

\subsection{Components}

RISK ANALYSER consists of the following components:

1) MEMORY - holds in storage the Risk Indicators categorized in LOTs of FDVs (SUBMEMORY for HEURISTIC LOTS), magnitudes of FDVs (SUBMEMORY for FDV MAGNITUDES); types of risks (SUBMEMORY for RISK IDENTITY); and recommendations for risks (SUBMEMORY for RECOMMENDER),

2) HEURISTC CALL - calls initially for LOT of Risk Indicators into working memory; matches each heuristic in $\mathrm{LOT}_{\mathrm{P}}$ with project characteristics. If there is no match, HEURISTIC CALL will call for LOT $_{\mathrm{P}+1}$ from MEMORY.

3) FDV CONFIRMATION - if there is a match between the Risk Indicators and the project characteristics, FDV CONFIRMATION will confirm from MEMORY the particular FDV that could prevail in the project.

4) CONFIDENCE VALUE - this is system-user interface that requests and accepts from user the confidence value by which the user believes the prevalence of the FDV is indicated. 
5) FDV MAGNITUDE - this call from MEMORY the likely possible value of the effect of the initial contract sum.

6) FDV SCORE - this calculates the score of the FDV according to the formula; FDV SCORE $=$ CONFIDENCE VALUE $*$ FDV MAGNITUDE

7) RISK IDENTITY - this identifies the specific risk from which the FDV emanates.

8) RISK SCORE - this calculates the cumulative sum of the FDV SCORES for all the FDVs emanating for each identified risk.

9) RISK REGISTER - this locates the level of the identified risk according to the value of its score in the risk register.

10) RECOMMENDER - this recommends, from MEMORY the appropriate measure that could be undertaken in order to mitigate the risk.

11) LEARNING MADULE - this accepts new knowledge for incorporation into the model in order to accommodate changing domain parameters.

\subsection{FRAMEWORK FOR THE KNOWLEDGE-BASED SYSTEM}

A Knowledge-Based System (KBS) can be defined as a computer system, which relies on extensive domain-specific knowledge for problem-solution (Dutta, 1993). The fulcrum of Knowledge-Based System development is to elicit domain-specific information from experts, represent such knowledge using an appropriate representation and incorporate such representation in a computer program for the purpose of solving human activity problems. According to Smith (1985), a Knowledge-Based System (KBS) develops computational models of human intelligence and reasons with judgmental, imprecise and qualitative knowledge as well as with formal knowledge of established theories. Dutta (1993) has distinguished expert systems as KnowledgeBased Systems in which the dominant source of knowledge comes from the experience and expertise of human experts whilst; generally, Knowledge-Based Systems could incorporate knowledge from experts as well as knowledge from other sources. Sharma (2013) has described how expert knowledge could be obtained from specialists or other sources of expertise such as texts, journal articles and databases. Bonnet et al (1988) have highlighted risk evaluation as one of the diagnostic problems that could be handled by an expert system.

The goal desired in this study is the construction of a Knowledge-Based System that could undertake the risk analysis of proposed construction projects for a selected client. The objectives are:

1) To identify the Fuzzy Decision Variables (FDVs) that give rise to the risks at the design stage

2) To write a program for the Knowledge-Based system using JAVA programming language

3) To implement the Knowledge-Based System Program

Dutta (1993) has described the general structure of Knowledge-Based Systems as comprising of three main components:

1) The Knowledge Base which serves as a repository of domain-specific knowledge

2) The Inference Engine which is responsible for controlling and directing the use of knowledge for problem solution

3) The User Interface module which serves as the interface between the user and the Knowledge-Based System.

This Knowledge-Based System would be modeled upon the conceptual framework delineated by the RISK ANALYZER model (Ibrahim, 2008 and Ibrahim, 2010).

Construction risk analysis consists of two distinct stages (Flanagan and Norman, 1993): 
(1) The identification of risks

(2) The evaluation of likely magnitudes of risk consequences and

The methodology adopted in this work comprises structures system analysis, rule-based reasoning and fuzzy logic. Structures system analysis models the environment from the perspective of the information flow through it (Keravnou and Johnson, 1986). In rule-based reasoning, conclusions are typically expressed in terms of possibilities based on past experiences and what is perceived as the most likely choice among alternatives (Teft, 1989). Fuzzy logic is an approach to approximate reasoning in which possibilistic rather than probabilistic quantifiers and truth values are associated with propositions (Zadeh, 1975).The KBS undertakes risk analysis for proposed construction projects as follows:

\subsection{Risk Identification}

The knowledge Base holds in storage the Risk Indicators categorized in lots of Fuzzy Decision Variables (FDVs), magnitudes of FDVs and types of risks. Ibrahim (2008) has described an approach that could be utilized in predicting risks in a construction project by perusing project data such as drawings, bills of quantities and specifications and estimating the prevalence of Fuzzy Decision Variables (FDVs). A Fuzzy Decision Variable (FDV) for a particular risk event denotes a condition in a risk environment, which predisposes the occurrence of that risk in the environment (Ibrahim, 2007; Bala and Yakubu, 2008). FDVs are used as variables for assessing monetary consequences of risks. The strength or density of an FDV indicates the likelihood by which that FDV could cause the occurrence of that risk. Therefore, the occurrence of a risk is precipitated if its FDVs are significant in concentration. The risk of unknown unknown (Smith, 1999) is indicated by the FDV of unknown unknown which is an unknown latent condition that cannot be defined, nor identified and is not estimable in terms of effect (examples: items of work covered by provisional sums and provisional quantities in the Bills of Quantities); yet it could precipitate concrete adjustment in the initial contract sum. The FDV of long contract period predicts the likelihood of occurrence of the risk of inflation.

The Inference Engine calls into working memory a lot of FDVs and selects the first Risk Indicator which it would attempt to match to a project characteristic identified through interaction with the user in the User Interface. This procedure is repeated for all the Risk Indicators domiciled in that particular lot of FDVs. If there is no match, the Inference Engine would the call for the second lot of FDVs and the same procedure is executed for all the Risk Indicators in the second lot. If there is a match, between any of the Risk Indicators in the first lot, the Inference Engine would confirm that the particular FDV covered by that lot is prevailing in the proposed project. The inference Engine would then request the user, through the User Interface, to provide the Confidence Value for the identified FDV.

Confidence Value denotes the expert's estimate of his belief in a particular assertion or conclusion (Ibrahim, 2008). Confidence Value is derived from Certainty Factor, which is a quantitative estimate of the relative strength of a conclusion drawn from uncertain premises using approximate inference (Buchanan and Shortcliffe, 1984 and Teft, 1989). Confidence Values are, in effect, membership functions in fuzzy logic; being the confidence vested in the belief that a particular statement or value is true. 


\subsection{Risk Evaluation}

The Fuzzy computer program for the evaluation of risk magnitudes in the selected domain has been adopted as a sub-program for the KBS (Ibrahim, 2013). For each FDV, the Inference Engine would call from the Knowledge Base the relevant value of the FDV magnitude as calculated using fuzzy set analysis. Fuzzy logic has been applied in creating decision-support and expert system in management and financial decisions (Sharma, 2011).

The KBS would convert the Confidence Value $C_{\text {initial }}$ of each FDV to value $C_{\text {final }}$ using the formula (Ibrahim. 2008):

$$
\mathrm{C}_{\text {final }}=5 \mathrm{C}_{\text {in }}
$$

The KBS would also convert $\mathrm{M}_{\text {initial }}$; the magnitude of each FVD into a value $\mathrm{M}_{\text {final }}$ using the formula (Ibrahim. 2008):

$$
\mathrm{M}_{\text {final }}=50 \mathrm{M}_{\text {initial }}
$$

The two numbers $\mathrm{C}_{\text {final }}$ and $\mathrm{M}_{\text {finalare then }}$ multiplied together to yield the FDV risk score For all identified FDVs in a lot, a cumulative Risk Score denoting the summation of all FDV risk scores for the lot would be calculated by the Inference Engine. The Inference Engine would subsequently rank the Risk Scores in a Risk Register in order to identify and rank the risks in the proposed project.

The KBS adopts the risk register of the Standards Association of Australia as shown in Table 1 below:

Table 1 Risk Register of the Standards Association of Australia

\begin{tabular}{|l|l|}
\hline Risk score & Level of risk \\
\hline $15-25$ & High risk \\
\hline $8-12$ & Significant risk \\
\hline $4-6$ & Moderate risk \\
\hline $1-3$ & Low risk \\
\hline 0 & No risk \\
\hline
\end{tabular}

Source: Thompson and Pretlove (2002)

The KBS would then announce each risk and its level of severity to the user.

The Graphic User Interface was built on the Oracle NetBeans IDE 7.3 Beta using panel swing container.

Each FDV with a set of risk indicators was placed on a panel. The indicators are exhibited as a grouped checklist with each item labeled as a risk indicator. The user peruses through the list of indicators for each FDV and then examines the contract documents for the proposed project (drawings, bills of quantities, specifications, etc).

The user selects a tick box to confirm that the risk indicator is prevailing in the risk environment and highlighted data box receives the Confidence Value inserted by the user against each ticked FDV. 
The first FDV is Inadequate Strategic Briefing. Its panel is shown in Plate I. Its risk indicators are as follows:

- Space likely to be converted to functional use

- Car shed likely to be constructed

- Roads and parking space likely to be constructed

- Foundation-laying ceremony likely to be conducted

- Entrance porch likely to be constructed

- Building likely to be unsuitable for future growth.

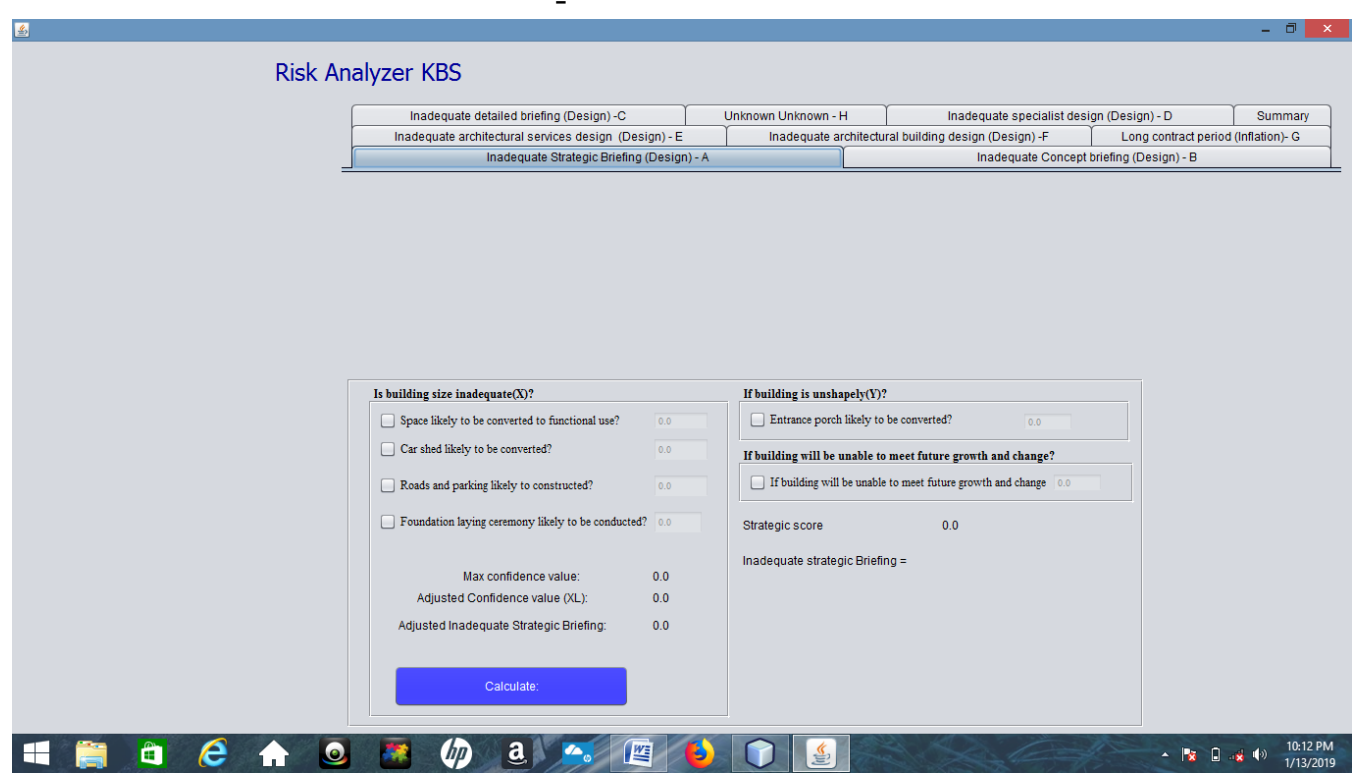

Plate 1 Panel showing the Derivation of the Magnitude of the FDV for Inadequate Strategic Briefing

In the source code, each risk indicator carries a Confidence Value included in the list [CV1,CV2, CV3, CV4, CV5, CV6]. A variable, Maximum_strategic, assumes the value of the highest Confidence Value in the list adjusted in accordance with equation (1).

Another value, magnitude_strategic is obtained by adjusting the crisp value of the percentage likely effect of Inadequate Strategic briefing (Ibrahim, 2008) in accordance with equation (2).

Another variable, Strategic_score is the calculated as follows:

Strategic_score $=$ Maximum_strategic $\times$ magnitude_strategic.

The Strategic_score variable represents the risk score of the FDV of Inadequate Strategic Briefing. Another variable, Design_score represents the risk score of the risk of design. Design_score is initialized to zero but the value of Strategic_score would be added to Design_score after computation.

On the second panel (Plate 2), the FDV of Inadequate Concept Briefing would similarly computated to yield the Fdv score of Concept_score which is then accumulated to Design_score. Subsequent panels would yield Detail_score, Specialists_score, Archservices_scoreandArchbuilding_score which would all be accumulated to Design_score. 
International Journal of Data Mining \& Knowledge Management Process (IJDKP) Vol.9, No.4, July 2019

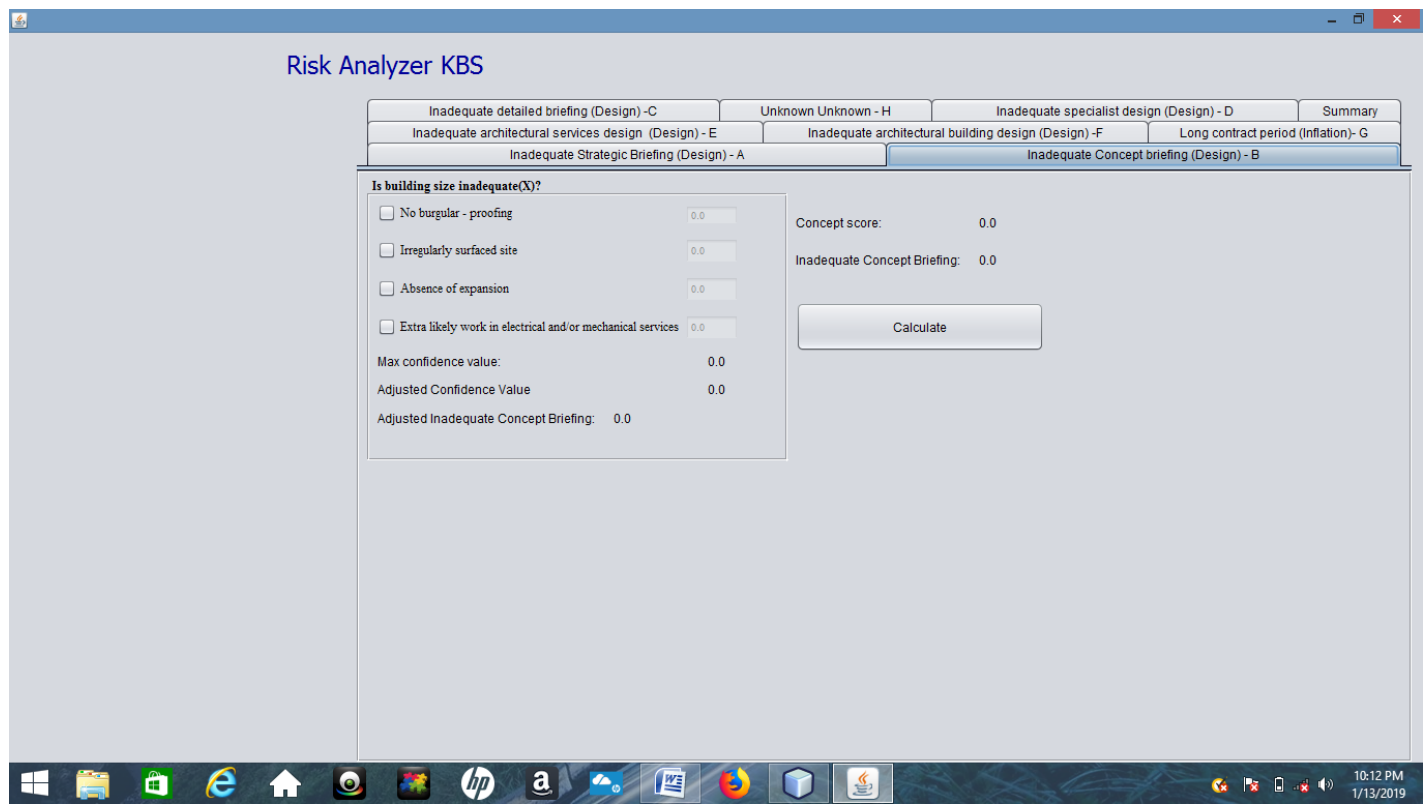

Plate 2 Panel showing the Derivation of the Magnitude of the FDV for Inadequate Concept Briefing

The seventh and eighth panels (Plates 2 \& 3) would compute Inflation_score and Unknown_score which represent the risk scores of Inflation risk and Unknown risk respectively.

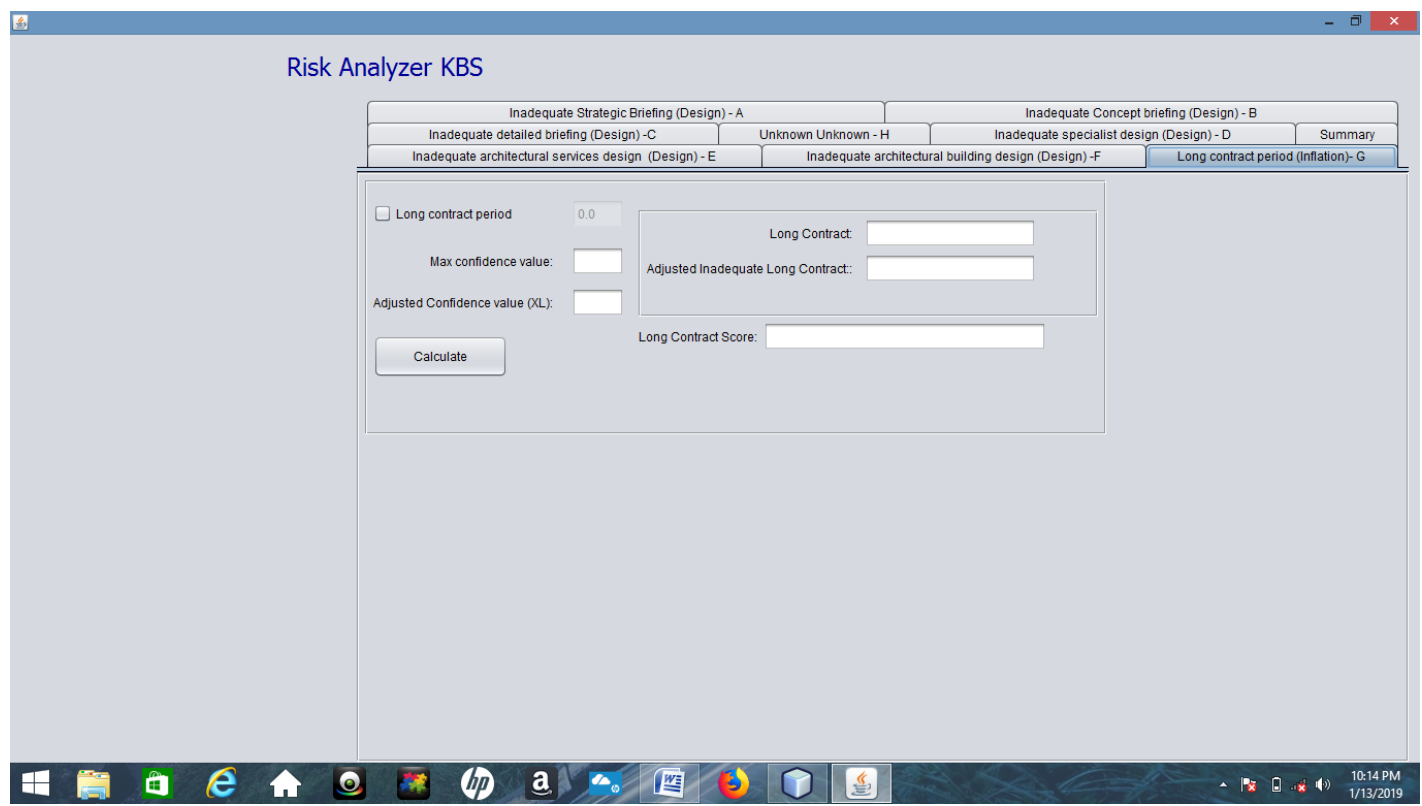

Plate 3 Panel showing the Derivation of the Magnitude of the FDV for Long Contract Period 




Plate 4 Panel showing the Derivation of the Magnitude of the FDV for Unknown Unknown

In the last panel (Plate 5), the KBS computes the interval of each risk score in the risk register and subsequently prints the type of risk (design, inflation or unknown) and the degree of risk exposure of the individual risks (high, significant, moderate, low or no risk).

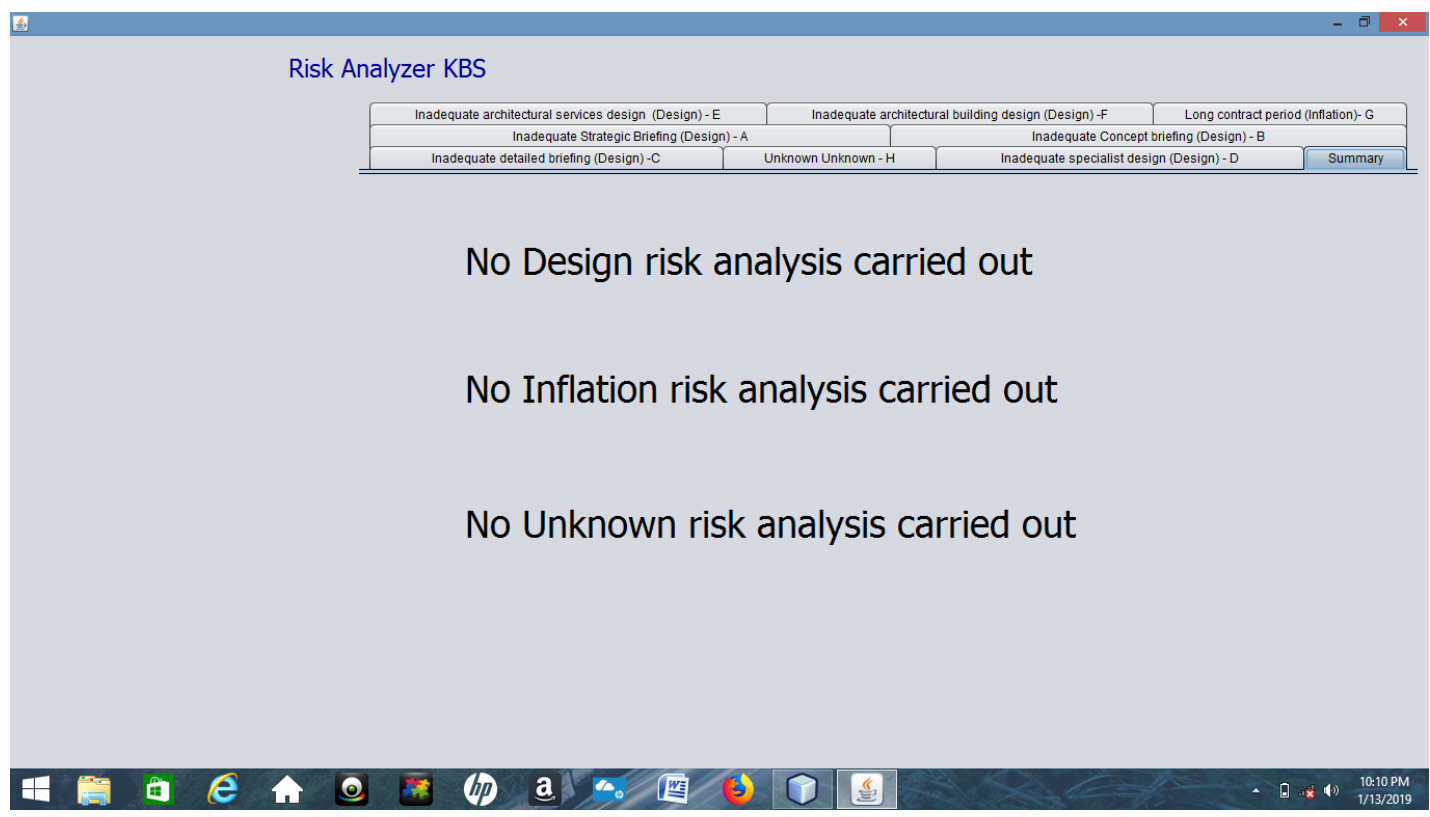

Plate 5 Panel showing the Types of Risks analyzed

\subsection{VALIDATION OF THE KBS}

Validation is the most restrictive, most arduous and most time consuming of all stages in the development cycle of the KBS (Bonnet et al, 1988). Validating the KBS would require the validation of its risk identification and risk evaluation processes. The risk identification process is 
logical and realistic because it is based upon the concept of detecting FDVs using risk indicators. The underlying precept for this approach is that the presence of at least one indicator is a sufficient indicator for the likely occurrence of an FDV (Ibrahim, 2008). This is analogous to the diagnosis of a multi-symptom disease; whereby the disease could manifest with one or more symptoms. In the case of risk analysis, the presence of at least an indicator is sufficient to confirm the likely occurrence of an FDV. Unlike human illness, risk in a construction project could betray no symptoms; hence any indicator that manifests itself at the pre-contract stage should be a portent indicator of the presence of the risk.

The risk evaluation component has been validated (Ibrahim, 2013). The Knowledge Base had been built from data derived from some five projects that had been executed by the client. The period of construction of the five projects commenced from September 1989 and ended October 1999.

The program was tested with two projects retrospectively for executed projects; a Lecture Theatre and an Administrative Block. The two projects had been executed from October 2000 to September 2013.

Table 2 gives predicted values of likely consequences of FDVs and the actual values obtained during the execution of the 1000 - seats lecture theatre.

Table 2 comparison between Predicted and Actual Values of the Likely Percentage Difference to the Initial Contract Sum of the 1000-Seats Lecture Theatre

\begin{tabular}{|l|l|l|l|}
\hline s/no. & $\begin{array}{l}\text { Fuzzy Decision } \\
\text { Variable }\end{array}$ & $\begin{array}{l}\text { Predicted Likely Percentage } \\
\text { Difference to the Initial } \\
\text { Contract Sum (\%) }\end{array}$ & $\begin{array}{l}\text { Actual Likely Percentage } \\
\text { Difference to the Initial } \\
\text { Contract Sum (\%) }\end{array}$ \\
\hline 1. & $\begin{array}{l}\text { Inadequate strategic } \\
\text { briefing }\end{array}$ & +2 & +0.16 \\
\hline 2. & $\begin{array}{l}\text { Inadequate concept } \\
\text { briefing }\end{array}$ & +5 & +1.71 \\
\hline 3. & $\begin{array}{l}\text { Inadequate specialist } \\
\text { consultants designs }\end{array}$ & +5 & +7.01 \\
\hline 4. & $\begin{array}{l}\text { Inadequate } \\
\text { architectural building } \\
\text { designs }\end{array}$ & +1 & +0.58 \\
\hline 5. & $\begin{array}{l}\text { Inadequate } \\
\text { architectural services } \\
\text { designs }\end{array}$ & +1 & +0.47 \\
\hline 6. & Long contract period & 0.00 & 0.00 \\
\hline 7. & Unknown unknown & -3 & -4.95 \\
\hline & TOTAL & +11.00 & +8.93 \\
\hline
\end{tabular}

Source: Ibrahim (2013)

Table 3 gives predicted values of likely consequences of FDVs and the actual values obtained during the execution of the Administrative Building 
International Journal of Data Mining \& Knowledge Management Process (IJDKP) Vol.9, No.4, July 2019

Table 3 Comparison between Predicted and Actual Values of the Likely Percentage Difference to the Initial Contract Sum of the Administration Building

\begin{tabular}{|l|l|l|l|}
\hline s/no. & $\begin{array}{l}\text { Fuzzy Decision } \\
\text { Variable }\end{array}$ & $\begin{array}{l}\text { Predicted Likely Percentage } \\
\text { Difference to the Initial } \\
\text { Contract Sum (\%) }\end{array}$ & $\begin{array}{l}\text { Actual Likely Percentage } \\
\text { Difference to Ine Initial } \\
\text { Contract Sum (\%) }\end{array}$ \\
\hline 1. & $\begin{array}{l}\text { Inadequate strategic } \\
\text { briefing }\end{array}$ & 0 & 0 \\
\hline 2. & $\begin{array}{l}\text { Inadequate concept } \\
\text { briefing }\end{array}$ & +5 & +5.24 \\
\hline 3. & $\begin{array}{l}\text { Inadequate specialist } \\
\text { consultants designs }\end{array}$ & 0 & +4.07 \\
\hline 4. & $\begin{array}{l}\text { Inadequate } \\
\text { architectural building } \\
\text { designs }\end{array}$ & 0 & 0 \\
\hline 5. & $\begin{array}{l}\text { Inadequate } \\
\text { architectural services } \\
\text { designs }\end{array}$ & 0 & 0 \\
\hline 6. & Long contract period & +17 & +13.21 \\
\hline 7. & Unknown unknown & -3 & -4.04 \\
\hline & TOTAL & +19 & +18.46 \\
\hline
\end{tabular}

Source: Ibrahim (2013).

For both projects, the total difference between predicted and actual values lies between plus minus 5\% range required for a quantity surveyor's estimate (Blok, 1982).

This paper is presenting the data for three more projects executed by the client between 2015 and 2018 in order to evaluate the performance of RISK ANALYZER five years after its development. Table 4 gives predicted values of likely consequences of FDVs and the actual values obtained during the execution of the Hostel Block I executed between 2015 and 2016

Table 4 Comparison between Predicted and Actual Values of the Likely Percentage Difference to the Initial Contract Sum of Hostel Block I

\begin{tabular}{|l|l|l|l|}
\hline s/no. & $\begin{array}{l}\text { Fuzzy Decision } \\
\text { Variable }\end{array}$ & $\begin{array}{l}\text { Predicted Likely Percentage } \\
\text { Difference to the Initial } \\
\text { Contract Sum (\%) }\end{array}$ & $\begin{array}{l}\text { Actual Likely Percentage } \\
\text { Difference to the Initial } \\
\text { Contract Sum (\%) }\end{array}$ \\
\hline 1. & $\begin{array}{l}\text { Inadequate strategic } \\
\text { briefing }\end{array}$ & 0.00 & 0.00 \\
\hline 2. & $\begin{array}{l}\text { Inadequate concept } \\
\text { briefing }\end{array}$ & 0.00 & -0.79 \\
\hline 3. & $\begin{array}{l}\text { Inadequate specialist } \\
\text { consultants' designs }\end{array}$ & 0.00 & -2.01 \\
\hline 4. & $\begin{array}{l}\text { Inadequate } \\
\text { architectural building } \\
\text { designs }\end{array}$ & 0.00 & 0.00 \\
\hline 5. & $\begin{array}{l}\text { Inadequate } \\
\text { architectural services } \\
\text { designs }\end{array}$ & 0.00 & +3.53 \\
\hline 6. & Long contract period & 0.00 & 0.00 \\
\hline 7. & Unknown unknown & -3.00 & -0.64 \\
\hline & TOTAL & $-3.00 \mathrm{~S}$ & +0.09 \\
\hline
\end{tabular}


International Journal of Data Mining \& Knowledge Management Process (IJDKP) Vol.9, No.4, July 2019

Source: Field work

Table 5 gives predicted values of likely consequences of FDVs and the actual values obtained during the construction of the Hostel Block II executed 2015 and 2017

Table 5 Comparison between Predicted and Actual Values of the Likely Percentage Difference to the Initial Contract Sum of Hostel Block II

\begin{tabular}{|l|l|l|l|}
\hline s/no. & $\begin{array}{l}\text { Fuzzy Decision } \\
\text { Variable }\end{array}$ & $\begin{array}{l}\text { Predicted Likely Percentage } \\
\text { Difference to the Initial } \\
\text { Contract Sum (\%) }\end{array}$ & $\begin{array}{l}\text { Actual Likely } \\
\text { Percentage Difference } \\
\text { to the Initial Contract } \\
\text { Sum (\%) }\end{array}$ \\
\hline 1. & $\begin{array}{l}\text { Inadequate strategic } \\
\text { briefing }\end{array}$ & 0.00 & +4.00 \\
\hline 2. & $\begin{array}{l}\text { Inadequate concept } \\
\text { briefing }\end{array}$ & 0.00 & -2.13 \\
\hline 3. & $\begin{array}{l}\text { Inadequate specialist } \\
\text { consultants' designs }\end{array}$ & 0.00 & +0.44 \\
\hline 4. & $\begin{array}{l}\text { Inadequate } \\
\text { architectural building } \\
\text { designs }\end{array}$ & 0.00 & 0.00 \\
\hline 5. & $\begin{array}{l}\text { Inadequate } \\
\text { architectural services } \\
\text { designs }\end{array}$ & 0.00 & +2.24 \\
\hline 6. & Long contract period & 0.00 & 0.00 \\
\hline 7. & Unknown unknown & -3.00 & -0.68 \\
\hline & TOTAL & -3.00 & +3.87 \\
\hline
\end{tabular}

Source: Fieldwork

Table 6 gives predicted values of likely consequences of FDVs and the actual values obtained for the construction of a two storey Office Block executed between 2017 and 2018

Table 6 comparison between Predicted and Actual Values of the Likely Percentage Difference to the Initial Contract Sum of the Two-storey Office Block

\begin{tabular}{|l|l|l|l|}
\hline S/no. & $\begin{array}{l}\text { Fuzzy Decision } \\
\text { Variable }\end{array}$ & $\begin{array}{l}\text { Predicted Likely Percentage } \\
\text { Difference to the Initial } \\
\text { Contract Sum (\%) }\end{array}$ & $\begin{array}{l}\text { Actual Likely Percentage } \\
\text { Difference to the Initial } \\
\text { Contract Sum (\%) }\end{array}$ \\
\hline 1. & $\begin{array}{l}\text { Inadequate strategic } \\
\text { briefing }\end{array}$ & 0.00 & -0.82 \\
\hline 2. & $\begin{array}{l}\text { Inadequate concept } \\
\text { briefing }\end{array}$ & +5 & +0.22 \\
\hline 3. & $\begin{array}{l}\text { Inadequate specialist } \\
\text { consultants' designs }\end{array}$ & 0.00 & -1.69 \\
\hline 4. & $\begin{array}{l}\text { Inadequate } \\
\text { architectural building } \\
\text { designs }\end{array}$ & 0.00 & +1.90 \\
\hline 5. & $\begin{array}{l}\text { Inadequate } \\
\text { architectural services } \\
\text { designs }\end{array}$ & +1.00 & -0.65 \\
\hline 6. & Long contract period & 0.00 & 0.00 \\
\hline 7. & Unknown unknown & -3 & -0.20 \\
\hline & TOTAL & +3 & -1.26 \\
\hline
\end{tabular}


Source: Fieldwork

For the last three projects (Hostel Block I, Hostel Block II and the two storey Office Block) executed between 2015 and 2018, the total difference between predicted and actual values lies outside the plus - minus 5\% range required for a quantity surveyor's estimate (Blok, 1982).

\subsection{DisCUSSION}

The two projects that had complied with the expectation of the KBS (where the total difference between predicted and actual values lies between the plus - minus 5\% range required for a quantity surveyor's estimate) could possibly share the same risk characteristics with the five projects whose data was used to build the KBS of RISK ANALYZER. This is because most of the FDVs in the database were detectable in the two projects. The fulcrum of knowledge -base system is to elicit domain-specific information, represent such knowledge using an appropriate representation and incorporate such representation in a computer program for the purpose of solving human activity problems (Ibrahim, 2008).

However, most of the FDVs were not detected were not detected in the analysis of the last three projects (Hostel Block I, Hostel Block II and two-storey office Block). The implication is that the domain risk characteristics have changed over the years. In the analysis of the three projects there were evidences that the client had become risk-conscious (minimizing the use of Provisional sums and Prime Cost Sums in the Bills of Quantities, undertaking full measurement wherever possible, and hedging against inflation by providing advance payments for mobilization). The characteristics of a domain could change (Ibrahim, 2008) with time; new FDVs could be added or old ones could become irrelevant; magnitudes of risk consequences could change as a result of change in risk attitude in the domain. It would be necessary for the RISK ANALYZER to 'learn' of new parameters encountered by the KBS through its Knowledge Acquisition Module; and subsequently incorporate the new knowledge into the Knowledge- Base in order to facilitate the solution of emerging, contemporary problems.

\subsection{CONCLUSION}

A Knowledge-Based System that is capable of soliciting for data from a user in order to identify the risks in proposed building projects, quantify the likely magnitudes of the risks and subsequently rank the risks in order of their significance has been developed from the RISK ANALYZER model. The Knowledge-Based System has been implemented and validated as a computer program. Provided that the risk characteristics for building projects for a particular client can be elicited and structured into the framework of Fuzzy Decision Variables, the Knowledge-Based System could be used to undertake the risk analysis of proposed building projects for the client.

Since human activity systems are dynamic, it is imperative that situations in which RISK ANALYZER is applied must conform to the domain characteristics initially envisaged during the development of the model. Otherwise, RISK ANALYZER must be able undertake self-learning in order to avoid giving faulty results when it is run. 


\section{REFERENCES}

[1] Bala, K. \& Yakubu, I. (2008) “The Application of Fuzzy Decision Variables for Evaluating Risk Associated Consequences in Construction Projects", Nigerian Journal of Construction Technology and Management, Vol.9, No.1, pp 42-49.

[2] Blok, F.G. (1982) “Contingency, Definition, Clarification and Probability", Proceedings of the 7th International Construction Engineering Congress ,Paper B-3, London, England.

[3] Bonnet, A.; Haton, J.P.; \& Truong-Ngoc, J.M. (1988) Expert System, Prentice-Hall International:UK.

[4] Buchanan, B.G. \& Shortcliffe, E.H. EDS (1984) Ruled-Based Expert Systems: The Mycin Experiments of the Stanford Heuristic Programming Project, Addison-Wesley: Reading, Masschusetts.

[5] Dutta, S. (1993) Knowledge Processing and Applied Artificial Intelligence, Butterworth-Heinemann Ltd. : Oxford

[6] Flanagan, R.E. \& Norman, G. (1993) Risk Management and Construction, Blackwell Scientific Publications: UK.

[7] Ibrahim, Y. (2007) "The Application of Knowledge Engineering in Risk Management: Heuristicbased Reasoning in the Qualitative Risk Analysis of Proposed Construction Projects", Journal of Construction Management and Engineering, Vol,.1 No.1, pp: 86-97.

[8] Ibrahim, Y. (2008) Modeling the Risk Analysis Process for Construction Projects in Nigeria, Unpublished PhD Thesis, Department of Building, Ahmadu Bello University, Zaria, Nigeria.

[9] Ibrahim, Y (2010) "Risk Analyzer: A Model for Undertaking Risk Analysis of Building Construction Projects in a Selected Domain", Proceedings of the Third World of Construction Project Management Conference held at Coventry University, October 20-22 2010, United Kingdom, pp 81-91.

[10] Ibrahim, Y. (2013) “A Fuzzy Computer Programme for Estimating Likely Consequences of Risks in Construction Projects: A Case Study of a Selected Client", Proceedings of the RICS COBRA conference held 10-12 September, 2013 at New Delhi, India.

[11] Keravnou, E.T. and Johnson, L. (1986) Competent Expert Systems, McGraw - Hill Book Company.

[12] Thompson, P.J. \& Pretlove, S.J. (2002) "Risk Management in the Delivery Suite. The Obstetrician and Gynaecologist", Journal for Continuing Professional Development, The Royal College of Obstetricians and Gynaecologists, Vol.4 No.1 pp 45-48.

[13] Sharma, P. (2011) Working with Artificial Intelligence, S. K. Kataria\& Sons: New Delhi

[14] Smith, R. (1985) Knowledge-Based System Concept, Techniques, Examples, from http://www.reidgsmith.com.Schlumberger-Doll Research, retrieved 26th January, 2015.

[15] Smith, N.J; Merna, T.; \& Jobling, P. (1999) Managing Risk for Construction Projects, Blackwell Science Ltd.: London, U.K.

[16] Teft, L. (1989) Programming in Turbo - Prolog, Englewood Cliffs, New Jersey: Prentice Hall.

[17] Zadeh, L. A. (1975) “Fuzzy Logic and Approximate Reasoning”, syntheses, 30, pp 407428. 


\section{AUTHOR}

Ibrahim Yakubu was born in Bauchi, Bauchi State, Nigeria. He attended Ahmadu Bello University, Zaria, Nigeria; University of Jos, Nigeria and Abubakar Tafawa Balewa University, Nigeria. He is a Registered Quantity Surveyor and a Professor of Construction Management at Abubakar Tafawa Balewa University, Bauchi, Nigeria. His research specialization is in Application of Information Technology to Construction Management. His hobbies include reading, writing and travelling. He is married with children. 